\title{
Affective state dependence and relative trait stability of perfectionism in sleep disturbances
}

\section{Dependência do estado afetivo e estabilidade relativa do traço do perfeccionismo nas perturbações de sono}

\author{
Berta R. Maia, ${ }^{1}$ Maria J. Soares, ${ }^{1}$ Ana T. Pereira, ${ }^{1}$ Mariana Marques, ${ }^{1}$ Sandra C. Bos, ${ }^{1}$ Ana Gomes, ${ }^{2}$ José \\ Valente, ${ }^{1}$ Maria H. Azevedo, ${ }^{1}$ António Macedo ${ }^{1}$
}

${ }^{1}$ Medical Psychology Institute, Faculdade de Medicina, Universidade de Coimbra, Portugal

${ }^{2}$ Department of Education, Universidade de Aveiro, Portugal

\begin{abstract}
Objective: To evaluate the degree of absolute change, relative stability and state dependence of trait perfectionism in sleep disturbances in a sample of university students. Method: Participants completed the Multidimensional Perfectionism Scale and two items concerning sleep difficulties. The mean age at $\mathrm{T} 0$ (baseline) was 19.59 years $(\mathrm{SD}=1.61$, range $=17-25)$ and $62.5 \%$ of the sample were female. Results: Absolute changes in self-oriented and socially-prescribed perfectionism were found. Relative stability was found for all perfectionism dimensions. Prior and concurrent sleep disturbances explained a significant amount of variance in perfectionism. Controlling for the effects of sleep measures, prior selforiented perfectionism and other-oriented perfectionism were the only significant predictors of subsequent self-oriented perfectionism and otheroriented perfectionism, at T1 and T2. Difficulties falling asleep at T1 and socially-prescribed perfectionism at $\mathrm{T} 0$ were significant predictors of socially-prescribed perfectionism at T1. Conclusion: Despite significant changes in perfectionism mean scores over the follow-up, the correlation analyses demonstrated that participants remained quite stable in regard to their relative levels of perfectionism. As concurrent difficulties initiating sleep also predicted concurrent socially-prescribed perfectionism, this seems to be one dimension of perfectionism with trait-state characteristics.
\end{abstract}

Descriptors: Evaluation; Affective symptoms; Students; Analysis of variance; Sleep disorders

\section{Resumo}

Objetivos: Avaliar o grau de mudança absoluta, de estabilidade relativa e dependência do estado do perfeccionismo nas perturbaçôes de sono numa amostra de estudantes universitários. Método: Os sujeitos completaram a Escala Multidimensional do Perfeccionismo e dois itens sobre dificuldades em dormir. Os dados foram recolhidos em três momentos de avaliação, separados por um intervalo de um ano acadêmico. A idade média dos sujeitos no TO era de 19,59 anos $(D P=1,61$, variação $=17-25) ; 62,5 \%$ eram mulheres. Resultados: Foram encontradas ao longo do follow-up mudanças absolutas para o perfeccionismo auto-orientado e para o perfeccionismo socialmente prescrito. Foi encontrada estabilidade relativa para todas as dimensóes do perfeccionismo. As dificuldades de sono prévias e concorrentes explicaram significativamente a variancia do perfeccionismo. Controlando o efeito das dificuldades em dormir, o perfeccionismo auto-orientado e o perfeccionismo orientado para o outro prévios foram os únicos preditores significativos de perfeccionismo auto-orientado e perfeccionismo orientado para o outro (T1 e T2). As dificuldades em iniciar o sono no T1 e o perfeccionismo socialmente prescrito prévio (TO) revelaram-se preditores significativos de perfeccionismo socialmente prescrito no T1. Conclusão: Apesar das mudanças significativas nas pontuaçoes médias de perfeccionismo ao longo do follow-up, as análises de correlação demonstraram que os participantes permaneceram relativamente estáveis nos seus niveis de perfeccionismo. Uma vez que as dificuldades em iniciar o sono concorrentes se revelaram um preditor significativo de perfeccionismo socialmente prescrito, esta é a dimensão do perfeccionismo que possui características traço-estado.

Descritores: Avaliação; Sintomas afetivos; Estudante; Análise de variância; Transtornos do sono

\section{Introduction}

Research has demonstrated that perfectionism is multidimensional in nature, that it has both intrapersonal and interpersonal aspects, and that this trait has adaptive/positive and maladaptive/negative components.

Hewitt and Flett developed the Multidimensional Perfectionism Scale (MPS/H\&F), which assesses three perfectionism dimensions. ${ }^{1}$
Self-oriented perfectionism (SOP) includes behaviors such as setting excessively high standards for oneself and stringently evaluating and censuring one's own behavior. Socially-prescribed perfectionism (SPP) relates to one's beliefs or perception that significant others "have unrealistic standards for them, evaluate them stringently, and exert pressure on them to be perfect". ${ }^{1}$
Submitted: June 2, 2010

Accepted: January 21, 2011

\section{Correspondence}

Berta Rodrigues Maia

Instituto de Psicologia Médica, Faculdade de Medicina da Universidade de Coimbra

Rua Larga, 3004-504 Coimbra, Portugal

Phone: 00351239857759 Fax: 00351239823170

E-mail: bmaia@fmed.uc.pt 
Other-oriented perfectionism (OOP) involves beliefs and expectations about the capabilities of others.

Perfectionism has been associated with psychological distress, including conditions such as depression and sleep problems. ${ }^{2-6}$ Lundh and Broman's cognitive model of insomnia proposes that sleep-interfering psychological processes (e.g. arousal, worries, and emotional conflicts) and sleep-interpreting psychological processes (e.g. sleep-related beliefs, attitudes, and perfectionist standards) are involved in an integrative fashion in the development and maintenance of insomnia. ${ }^{7}$

The few studies on the role of perfectionism as a psychological vulnerability to sleep disturbances have reported positive associations. Using the MPS proposed by Frost et al., ${ }^{8}$ Lundh et al. ${ }^{4}$ found a significant association between perfectionism, sleep problems, and concerns about the negative consequences of insufficient sleep in a sample of healthy subjects. Vincent and Walker, ${ }^{6}$ comparing adults with chronic insomnia with healthy controls, found that insomniacs were more perfectionist, reporting more doubts about actions, concern over mistakes, and higher levels of parental criticism. In a recent longitudinal study, we found that SPP was a reliable predictor of sleep disturbances in an undergraduate student sample. ${ }^{3}$ However, the nature of the relationship between personality traits and sleep disturbances is still unclear. ${ }^{9}$ If perfectionism may lead to sleep difficulties, it may be true that such difficulties might influence/reinforce perfectionist cognitions. Someone who has been having sleep difficulties/problems will worry about not having the same daily performance, and might make their perfectionism goals stricter, not only in relation to sleep (e.g., "I must get some sleep tonight"), but also in regard to daily activities (e.g., "Today I must complete that task, even though I did not get enough rest").

An important hurdle to overcome if we are to propose perfectionism as psychological vulnerability involves the issues of trait stability (is perfectionism a relatively stable trait?) and state dependence (are perfectionist characteristics, which predispose to sleep difficulties, only problem-related i.e., are they only high when one has sleep problems, and do they decrease when these problems improve or remit?). To clarify these issues, Santor et al. made a distinction between absolute change and relative stability. ${ }^{10}$ The first concept emphasizes the extent to which personality mean scores change over time, whereas the second concept emphasizes the degree to which the relative differences among individuals remain the same over time. Pure trait stability exists if prior perfectionism is the sole significant predictor of subsequent perfectionism, after controlling for the effects of prior and concurrent sleep difficulties. Pure state dependence is present if only prior and concurrent sleep difficulties predict subsequent perfectionism, with no prior perfectionism effect. If prior perfectionism dimensions, along with prior and/or concurrent sleep disturbances, predict concurrent perfectionism, support for a state-trait characteristic is found. This model combines state dependence effects and trait stability. Therefore, perfectionist personality characteristics associated with vulnerability to sleep difficulties may persist over time, but sleep problems may increase their visibility and detection.

Results from three studies in the field of perfectionism found a high degree of relative trait stability and a small, albeit significant, degree of state dependence, supporting the state and trait characteristics of the construct in both clinical samples with major depression ${ }^{11-13}$ and in a non-clinical sample of students with self-reported depressive symptoms. ${ }^{12}$

The purpose of the present study was to evaluate, for the first time, perfectionism state dependence, trait stability, or state-trait dependence in association with sleep disturbances, controlling for the effects of prior and concurrent sleep problems. Due to the increasing rates of sleep disruption/insomnia and its association with daytime impairment and poor quality of life, this study may have clinical implications.

\section{Method}

The research project was reviewed and approved by the Medical Ethics Review Committee of the University Hospital of Coimbra. ${ }^{14}$

The voluntary nature and general format of the study were explained to the faculty of the courses of medicine, dentistry, and humanities of the University of Coimbra, and all agreed to conduct the study. With their approval, participants were given time at the beginning or end of a class session to fill in the survey questionnaires, which took approximately 25 minutes. All students present in class returned the questionnaires. Data were collected at three different moments separated by intervals of one academic year (2000/2001,2001/2002, 2002/2003), avoiding the exam period between October and November. The first moment was considered as baseline (T0), T1 refers to the first year of follow-up, and T2 to the second year of the study's follow-up.

\section{Participants}

The characteristics of the sample are presented in Table 1 . The mean age (Standard Deviation/SD) of participants at T0 was 19.59 years $(S D=1.61$; range $=17-25)$. The majority of the students at each time were single. Of the students assessed at T0, $65 \%$ and $48.5 \%$ completed the same measures after one and two years, respectively. An explanation for the attrition rates observed in the present study could be the fact that, in the third year of medical school, a considerable number of modules take place at the university hospital instead of at school. Classes at the hospital usually require clinical observations and interviews with patients and, therefore, less time is available at the end or beginning of classes for participation in research studies.

\section{Measures}

\section{Multidimensional Perfectionism Scale (H\&F-MPS)}

The H\&F-MPS is a self-report measure of perfectionism composed of three dimensions: SOP, SPP, and OOP. The scale has 45 items and respondents rate their agreement with each item on a 7-point scale ranging from "strongly disagree" (score 1) to "strongly agree" (score 7). Theoretically, scores may range from 45 to 315. Higher scores indicate greater perfectionism. In its Portuguese 


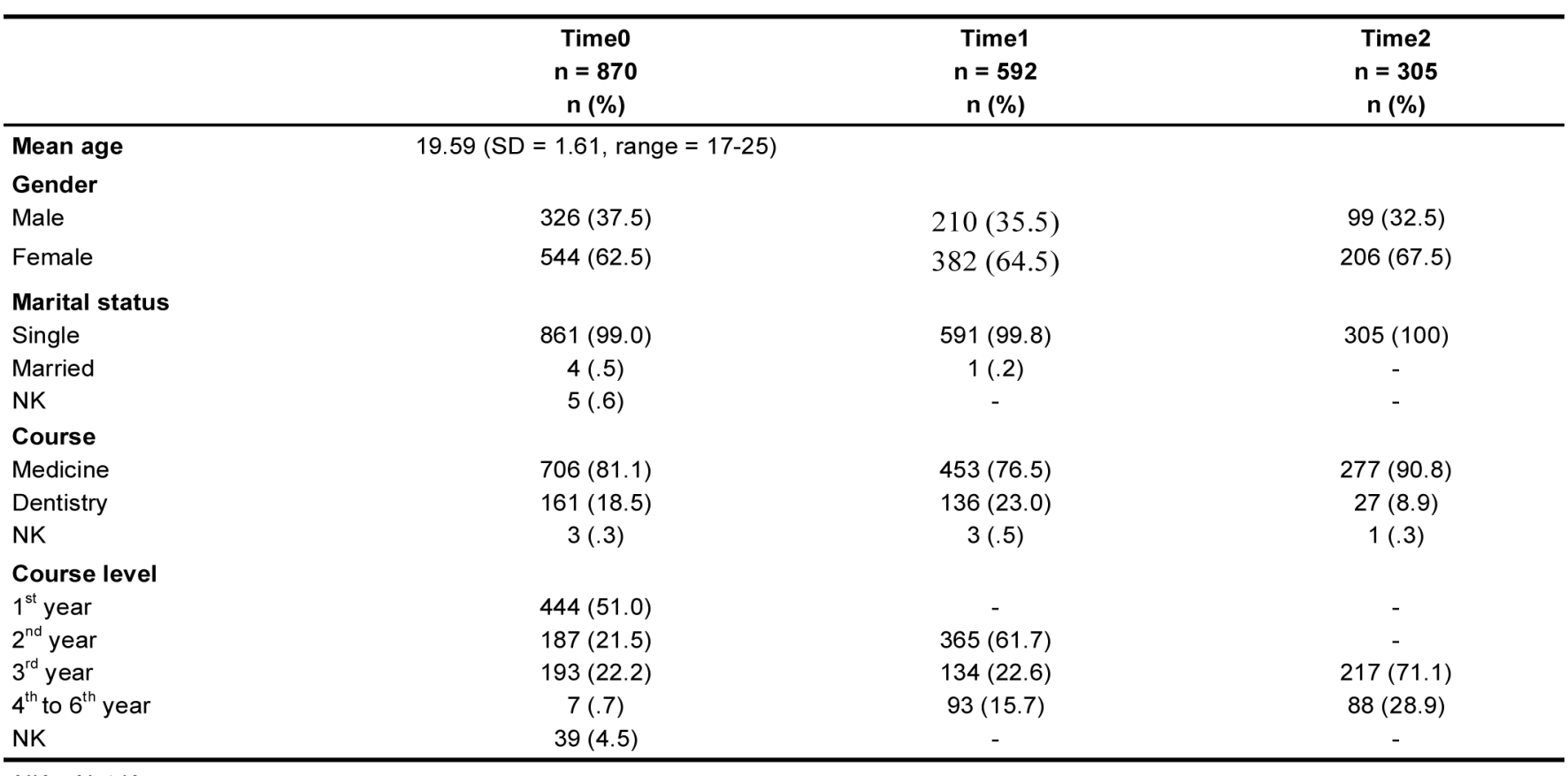

NK $=$ Not Known

version ${ }^{15}$ the MPS total score derived from the sum of individual item scores with a high internal consistency (Cronbach's alpha = $0.88)$, and the test-retest reliability over four weeks $(\mathrm{n}=293)$ was 0.84 (Pearson's $r, \mathrm{p}<0.001$ ). The internal consistency indicators (Cronbach's alpha) of the subscales were: SOP (18 items) = 0.89; $\mathrm{SPP}(15$ items $)=0.84$; and $\mathrm{OOP}(8$ items $)=0.66$.

\section{Sleep disturbances}

Two items presented as statements were used to assess sleep disturbances: (1) "I have difficulty in falling asleep" (Difficulties Initiating Sleep, DIS), and (2) "I wake up many times during the night” (Difficulties Maintaining Sleep, DMS). Each item was scored on a 5-point scale ranging from 0 (never) to 5 (always). In addition to scores obtained for DIS and DMS, an overall sleep disturbance index (SDI) was calculated from the sum of the scores of the individual items (possible range 0-10; Cronbach's alpha = 0.64). Higher scores indicated greater subjectively-experienced sleep disturbance. The test-retest reliability indicator (Pearson's $r$ ) over four weeks were 0.64 ( $p<0.001$ ) for DIS; 0.59 ( $p<0.001)$ for DMS; and $0.72(\mathrm{p}<0.001)$ for SDI scores.

\section{Statistical analyses}

We used descriptive statistics and parametric tests when variables were normally distributed. Where normal distribution could not be assumed, non-parametric tests were used. To assess the absolute stability of perfectionism and sleep measures over time, means were compared using paired sample $t$ tests for two repeated assessments (T0 and T1) or one-way ANOVA for three repeated measures (T0, T1 and T2) (Table 2 and 3). Perfectionism was the repeated measure in the time factor, and sleep was the independent variable.

To avoid the controversy surrounding the assumption of sphericity in the interpretation of ANOVA results, the Wilks Lambda multivariate test ${ }^{16}$ was used. To control for the familywise error rate across the three pairwise comparisons, the Holm's

Table 2 - Changes in mean (SD) perfectionism and sleep scores at T0 and T1 $(n=592)$

\begin{tabular}{|c|c|c|c|c|c|}
\hline Variable & $\begin{array}{l}\text { Time0 } \\
\text { M (SD) }\end{array}$ & $\begin{array}{l}\text { Time1 } \\
\text { M (SD) }\end{array}$ & $\mathbf{t}$ & df & p \\
\hline SOP & $82.42(14.90)$ & $79.78(14.92)$ & 5.274 & 1.549 & $<0.001$ \\
\hline SPP & $44.59(12.28)$ & $43.07(12.16)$ & 3.981 & 1.547 & $<0.001$ \\
\hline OOP & $44.96(6.98)$ & $45.26(7.28)$ & -1.059 & 1.561 & 0.290 \\
\hline SDI & $2.87(1.61)$ & $2.84(1.60)$ & 0.562 & 1.590 & 0.574 \\
\hline DIS & $1.70(1.06)$ & $1.61(1.04)$ & 2.200 & 1.590 & 0.028 \\
\hline DMS & $1.18(.80)$ & $1.23(0.80)$ & -1.535 & 1.591 & 0.125 \\
\hline
\end{tabular}

Paired-Sample $t$ Test. $M=$ mean; $S D=$ standard deviation; $S O P=$ Self-Oriented Perfectionism; SPP = Socially-Prescribed Perfectionism; OOP = Other-Oriented Perfectionism; $S D I=$ Sleep Disturbance Index; DIS = Difficulty Initiating Sleep; DMS = Difficulty Maintaining Sleep . 
Table 3 - Changes in mean (SD) perfectionism and sleep scores at T0, T1, and T2 ( $n=305)$

\begin{tabular}{|c|c|c|c|c|c|c|c|}
\hline Variables & $\begin{array}{c}\text { Time } 0 \\
\text { M (SD) } \\
(0)\end{array}$ & $\begin{array}{c}\text { Time } 1 \\
\text { M (SD) } \\
(1)\end{array}$ & $\begin{array}{c}\text { Time } 2 \\
\text { M (SD) } \\
(2)\end{array}$ & $F(b)$ & $\mathbf{p}$ & $x^{2}$ & Comparisons (a) \\
\hline SOP & $82.45(14.95)$ & $79.95(14.64)$ & $77.87(16.13)$ & 14.797 & $<0.001$ & 0.100 & $0>1^{* *}, 2^{* *} ; 1>2^{* *}$ \\
\hline SPP & $45.25(13.19)$ & $43.58(12.86)$ & $43.07(12.35)$ & 7.817 & $<0.001$ & 0.054 & $0>1^{* *}, 2^{* *} ; 1>2^{* *}$ \\
\hline OOP & $44.49(7.11)$ & $44.71(7.34)$ & $45.18(7.11)$ & 1.518 & 0.221 & 0.011 & - \\
\hline SDI & $2.92(1.60)$ & $2.89(1.59)$ & $2.07(1.39)$ & 67.020 & $<0.001$ & 0.307 & $2<0^{\star *}, 1^{\star \star}$ \\
\hline DIS & $1.69(1.07)$ & $1.65(1.09)$ & $1.67(1.13)$ & 0.327 & 0.721 & 0.002 & - \\
\hline DMS & $1.23(0.77)$ & $1.24(0.75)$ & $1.28(0.84)$ & 0.643 & 0.526 & 0.004 & - \\
\hline
\end{tabular}

(a) Pairwise comparisons of means with Holm's sequential Bonferroni correction. SOP = Self-Oriented Perfectionism; SPP = Socially-Prescribed Perfectionism; $O O P=$ Other-Oriented Perfectionism; SDI = Sleep Disturbance Index; DIS = Difficulty Initiating Sleep; DMS = Difficulty Maintaining Sleep.

${ }^{*} p<0.05 ;{ }^{* *} p<0.01$.

sequential Bonferroni correction procedure was used. To compare continuous variables between two groups, the Student's $t$ test was applied.

To assess the relative stability of perfectionism, Pearson correlations (test-retest) (Table 4) and hierarchical regression analyses with ordered sets of predictors were calculated. To analyse Pearson correlation coefficients, the Cohen ${ }^{17}$ criteria were applied: a 0.10 correlation coefficient was considered small; a 0.30 coefficient was considered moderate; and a coefficient $\geq 0.50$ was considered high. Regression analyses were performed using SOP, SPP, and OOP as dependent variables, and sleep and perfectionism data were taken as independent variables. For example, at one-year of follow-up regression analyses were performed considering SOP (T1) as the dependent variable, and predictors were entered in separate blocks as follows: concurrent DIS/DMS (T1), prior DIS/ DMS (T0), and prior SOP (T0). These analyses were repeated replacing DIS/DMS by SDI.

The same analyses were performed for each dependent variable or perfectionism dimension ( $3 \times 2=6$ analyses, see Table 5). At the two-year follow-up, regression analyses were performed in a similar way, i.e. SOP (T2) as the dependent variable and predictors entered in separate blocks, following the same order described: concurrent DIS/DMS (T2), prior DIS/DMS at T0, and prior DIS/DMS at T1 as a block; prior SOP at T0 and prior SOP at T1 as a block. Once more these analyses were repeated replacing DIS/DMS by SDI and changing the dependent variable according to the perfectionism dimension ( $3 \times 2=6$ analyses see Table 6 ). Partial correlations were used to study the association between a dependent variable and a predictor variable, controlling for the effects of other predictors. A p value of $<0.05$ was considered statistically significant.

\section{Results}

Participants who were followed-up at T1 had higher SOP at $\mathrm{T} 0$ than participants who were not followed-up $(\mathrm{M}=82.5$, $\mathrm{SD}=14.90$ vs. $\mathrm{M}=79.10 ; \mathrm{SD}=16.79, \mathrm{t}=-2.820 ; \mathrm{p}=0.005)$. Apart from this observation, no other significant differences were found between groups followed-up and not followed-up at T0, $\mathrm{T} 1$, and $\mathrm{T} 2$.

\section{Absolute stability of perfectionism and sleep mea- sures}

Results of paired sample $t$ tests and ANOVA are presented in Tables 2 and 3. A significant effect of time was found for SOP and SPP, suggesting a relevant decrease in most of the perfectionism variables over time from T0 to T2 (with the exception of OOP). With respect to sleep measures, the results showed a less consistent pattern across time. There was a significant decrease in DIS scores from T0 to T1 (mean $=1.70, \mathrm{SD}=1.06$ vs. mean $=1.61, \mathrm{SD}=1.04, \mathrm{t}=2.2, \mathrm{p}=0.028)$, as well as a decrease in SDI scores from T0 to T2 (T0, $\mathrm{M}=2.92, \mathrm{SD}=1.60 ; \mathrm{T} 1, \mathrm{M}=$ $2.89, \mathrm{SD}=1.59 ; \mathrm{T} 2, \mathrm{M}=2.07, \mathrm{SD}=1.39 ; \mathrm{p}<0.001)$. Wilks' Lambda values of $0.900,0.946,0.693$, with a significance value $<0.001$, were obtained for SOP, SPP, and SDI. Therefore, there is a statistically significant decrease in SOP, SPP, and SDI scores from $\mathrm{T} 0$ to $\mathrm{T} 2$.

\section{Relative stability of perfectionism and sleep mea-} sures

\section{Test-retest correlations}

Pearson correlation coefficients between DIS, DMS, and SDI scores at all follow-up times are presented in Table 4. Correlation coefficients across the three moments waves showed relative stability for SOP, SPP, and OOP (ranging from 0.51 to 0.79 , p $<0.001$ ). The lowest coefficients were found for OOP (ranging from 0.51 to $0.61 ; \mathrm{p}<0.001$ ) and the highest for SPP (ranging from 0.73 to $0.79 ; \mathrm{p}<0.001)$. SOP coefficients ranged from 0.60 to 0.75 ( $\mathrm{p}<0.001)$. A relative stability in sleep measures was also found, with results showing that correlation coefficients for DIS $(\mathrm{r}=0.55$ to $\mathrm{r}=0.66 ; \mathrm{p}<0.001)$ were higher than the coefficients for DMS ( $r=0.46$ to $r=0.51, p<0.001)$. SDI coefficients ranged from 0.49 and $0.58(\mathrm{p}<0.001)$. Considering correlation coefficients between perfectionism and sleep measures across the three moments waves, modest but nonetheless significant correlations were found for SPP (ranging from 0.16 to 0.33 ; p $<0.01$ ). When considering correlations between SOP and sleep measures, a less consistent pattern was observed, with several significant small correlations (ranging from $0.09, \mathrm{p}<0.05$, to $0.17, \mathrm{p}<0.01)$. 
Regression analyses - one year of follow-up

The results of the regression analyses for oneyear of follow-up are presented in Table 5. With respect to SOP, concurrent SDI and concurrent DIS/DMS explained a significant amount of the total variance in SOP at T1 $(1.1 \%[\mathrm{~F}(1,546)$ $=6.16, \mathrm{p}=0.013]$ and $1.1 \%[\mathrm{~F}(2,546)=3.08$, $\mathrm{p}=0.047])$. However, partial correlations indicated that, after controlling for the effect of concurrent and prior SDI and DIS/DMS, prior SOP was the only significant predictor of SOP at T1 ( $<<0.001)$. The percentage of variance explained by prior SOP was $46.5 \%$.

In regard to SPP, a different pattern emerged with both prior and concurrent sleep measures explaining a significant amount of the total variance at $\mathrm{T} 1$. Results showed that concurrent SDI and DIS/DMS explained 6.8\% [F(1,549) $=36.62, \mathrm{p}<0.001]$ and $6.8 \%[\mathrm{~F}(2,544)=$ $19.85, \mathrm{p}<0.001]$, respectively, of the total variance in SPP at T1; prior DIS/DMS explained an additional 2.3\% $[\mathrm{F}(2,542)=6.86$, $\mathrm{p}=0.001]$. After controlling for the effect of sleep measures (SDI or DIS/DMS), SPP at T0 accounted for a significant amount of SPP total variance at $\mathrm{T} 1$, with percentages ranging from $45.9 \%$ to $46.1 \%$. Although a significant contribution of concurrent and prior sleep measures was observed for the explanation of the variance in SPP at T1, partial correlations indicated that the useful significant predictors of total SPP variance were concurrent DIS $(\mathrm{p}=0.049)$ and previous SPP $(\mathrm{p}=0.001)$. Considering the variable OOP, prior OOP was the only significant predictor of subsequent OOP at $\mathrm{T} 1$ and $\mathrm{T} 2$.

In summary, at T1, after controlling for SDI and DIS/DMS at T0 and T1, baseline MPS dimensions remained significant predictors of the correspondent perfectionism measures at T1. Although sleep measures had a significant effect on the explanation of the residual variance in all MPS dimension scores at T1 (except for OOP), only concurrent DIS was a significant predictor of SPP at T1.

\section{Regression analyses - two years of follow-up}

Considering the regression analyses performed at T2 (Table 6), results were similar to those obtained at T1. For SOP scores at T2, only concurrent DIS/DMS explained $4.1 \%$ of the 
total variance in SOP. Prior sleep measures had no significant effects. As for SPP, prior and concurrent SDI and concurrent DIS/DMS contributed for a significant amount of the total variance at T1, explaining $7.2 \%, 5.4 \%$, and $12.1 \%$ of the total variance, respectively. With respect to OOP scores at T2, neither concurrent nor prior sleep measures had significant effects on OOP. However, after controlling for the effect of sleep measures, prior perfectionism scores (T0 and T1) explained a significant variance of perfectionism at T2. Prior SOP explained 52.2\% and 54.7\% of the total variance in SOP at T2, prior SPP explained $52.8 \%$ and $53.9 \%$ of the total variance in SPP at T2, and prior OOP explained between $41.5 \%$ and $42.2 \%$ of the total variance in OOP at T2. Results from partial correlations also showed that the significant predictors of perfectionism dimensions and total scores at T2 were the correspondent prior (T0/T1) perfectionism measures $(\mathrm{p}<0.01$ in all cases).

\section{Discussion}

The aim of the present study was to investigate the degree of absolute change, relative trait stability, and state dependence of perfectionism dimensions, encompassing adaptive and maladaptive facets of the construct.

We found significant decreases in SOP and SPP at one and two year's follow-up. Sleep measures revealed less consistency along the follow-up (a decrease in DIS from T0 to T1 was seen). Accordingly, we cannot state that perfectionism scores changed in the context of changes in sleep disturbances. Despite substantial changes in perfectionism mean scores (SOP, SPP) over the follow-up assessments, the correlation analyses demonstrated that participants remained quite stable in their relative levels of perfectionism. The strong correlations found between perfectionism dimensions over time are an indicator of relative trait stability.

Correlation analyses also showed that sleep measures were poorly or moderately correlated with perfectionism dimensions. As hypothesized, SPP was the only perfectionism dimension that showed a consistent pattern of association with all the sleep measures. The correlations found, although modest, were all significant. A less consistent pattern was found for SOP measures over time, with small significant correlation coefficients. These findings, although lending some support to the adaptive/ maladaptive distinction of perfectionism, provide limited support to the state dependence hypothesis. ${ }^{12}$ Stronger correlations with SDI, DIS, and DMS scores were found for SPP compared to the other perfectionism dimensions, which indicates that this is the most maladaptive aspect of this specific dimension in sleep disturbances.

Additionally, regression analyses indicated that concurrent sleep measures accounted for little of the SOP variance at T1 and T2. The fact that some of the residual variance in SOP was significantly explained by the variance in sleep measures is not completely surprising. Lundh et al., ${ }^{4}$ comparing insomniacs and controls, also found a significant association between insomnia and concern over mistakes and personal standards; and Azevedo et al. ${ }^{2}$ found small

Table 5 - Relative stability of perfectionism dimensions accounting for SDI, DIS, and DMS at baseline (T0) and one year of follow-up (T1)

\begin{tabular}{|c|c|c|c|c|c|c|}
\hline $\begin{array}{l}\text { Dependent } \\
\text { variable }\end{array}$ & $\begin{array}{c}\text { Predictor } \\
\text { variable }\end{array}$ & R2 & $\begin{array}{c}\mathbf{R}^{2} \\
\text { adjusted }\end{array}$ & $\begin{array}{c}\mathrm{R} 2 \\
\text { change }\end{array}$ & $F$ & $p$ \\
\hline \multicolumn{7}{|l|}{ SOP (1) } \\
\hline & SDI (1) & 0.011 & 0.009 & 0.011 & 6.158 & 0.013 \\
\hline & SDI (0) & 0.013 & 0.010 & 0.002 & 1.307 & 0.253 \\
\hline & SOP $(0)$ & 0.479 & 0.476 & 0.465 & 486.088 & $<0.001$ \\
\hline & DIS/DMS (1) & 0.011 & 0.008 & 0.011 & 3.079 & 0.047 \\
\hline & DIS /DMS (0) & 0.014 & 0.007 & 0.003 & 0.781 & 0.458 \\
\hline & $\operatorname{SOP}(0)$ & 0.479 & 0.474 & 0.465 & 484.929 & $<0.001$ \\
\hline \multicolumn{7}{|l|}{ SPP (1) } \\
\hline & SDI (1) & 0.068 & 0.066 & 0.068 & 39.619 & $<0.001$ \\
\hline & SDI (0) & 0.088 & 0.085 & 0.021 & 12.344 & $<0.001$ \\
\hline & $\operatorname{SPP}(0)$ & 0.549 & 0.547 & 0.461 & 555.246 & $<0.001$ \\
\hline & DIS/DMS (1) & 0.068 & 0.065 & 0.068 & 19.850 & $<0.001$ \\
\hline & DIS/DMS (0) & 0.091 & 0.084 & 0.023 & 6.864 & $<0.001$ \\
\hline & $\operatorname{SPP}(0)$ & 0.550 & 0.545 & 0.459 & 550.788 & $<0.001$ \\
\hline \multicolumn{7}{|l|}{ OOP (1) } \\
\hline & SDI (1) & 0.000 & -0.002 & 0.000 & 0.016 & 889 \\
\hline & SDI (0) & 0.000 & -0.004 & 0.000 & 0.002 & 0.966 \\
\hline & $\mathrm{OOP}(0)$ & 0.299 & 0.295 & 0.299 & 237.217 & $<0.001$ \\
\hline & DIS/DMS (1) & 0.008 & 0.004 & 0.008 & 2.169 & 0.115 \\
\hline & DIS /DMS (0) & 0.008 & 0.001 & 0.000 & 0.032 & 0.968 \\
\hline & $\operatorname{OPP}(0)$ & 0.303 & 0.297 & 0.295 & 235.162 & $<0.001$ \\
\hline
\end{tabular}

SOP = Self-Oriented Perfectionism; SPP = Socially-Prescribed Perfectionism; OOP = Other-Oriented Perfectionism; SDI = Sleep Disturbance Index; $D I S=$ Difficulty Initiating Sleep; DMS = Difficulty Maintaining Sleep. 
but significant associations between difficulties initiating sleep, difficulties maintaining sleep, and overall sleep disturbance and SOP, particularly with items related to setting high standards and concern over mistakes. In most psychopathological conditions or symptoms, the negative role of perfectionism as a risk factor has been established essentially in respect to SPP. In contrast, SOP has been described mostly as adaptive. ${ }^{18}$ Although this is partially true, the view of SOP as a positive dimension is a matter of controversy. According to some studies ${ }^{19}$ SOP could interact with negative achievement-related life events to predict dysfunctional outcomes. Our sample included medical students, and achievement-related stressors are likely to be more prominent in this population. Nevertheless, our results are consonant with the view that SOP is more adaptive than maladaptive and, in this sense, they agree with the hypothesis that adaptive perfectionism dimensions have stronger pure trait stability. ${ }^{10}$ Cox and Enns, in a study about absolute change and relative stability of perfectionism in depression, found similar results. ${ }^{11}$ SOP revealed a small but significant degree of affective state dependence, along with a high degree of relative trait stability.

A strong association between SPP and sleep disturbances is well documented in previous studies. ${ }^{2,3}$ Therefore, as expected, our findings indicate that the amount of SPP variance explained by sleep measures was substantially higher than that of SOP. Additionally, we observed that both concurrent and prior sleep measures made a significant contribution to the explanation of SPP variance. "These results are consistent with the view that maladaptive dimensions of perfectionism represent enduring psychological vulnerabilities (trait stability) that are elevated or exacerbated by certain conditions (state dependence"11). Even though a significant amount of the variance in follow-up perfectionism scores could be explained by sleep difficulties (except for OOP), the greatest amount of variance in perfectionism indicators was explained by prior corresponding perfectionism scores. Moreover, after controlling for the effects of prior and concurrent sleep difficulties, prior SOP and OOP significantly predicted corresponding perfectionism measures, one and two years after baseline. These findings are in accordance with the idea of pure trait stability.

As concurrent SPP was predicted by prior SPP, but also by concurrent sleep disturbances (DIS), this perfectionism dimension shows evidence of trait-state characteristics. Thus, in this sample of young adults, we found support for both relative trait stability and for state dependence effects, findings that are corroborated by previous clinical ${ }^{10,12}$ and non-clinical studies. ${ }^{11} \mathrm{SPP}$ has more insomnia state-trait characteristics, and SOP and OOP are more enduring and persistent traits, and consequently less related to insomnia. It may be possible that SPP plays a causal role in the development of sleep disturbances, and that sleep disturbances and the associated daytime dysfunction may influence/reinforce SPP. SPP is characterized by the setting of "unattainably high standards, the inability to take pleasure in one's performance and uncertainty about one's capabilities". ${ }^{20}$ Additionally, socially prescribed perfectionists tend to adopt maladaptive coping styles (cognitive rumination over mistakes and imperfections, tendency

Table 6 - Relative stability of perfectionism dimensions accounting for SDI, DIS, and DMS at baseline (T0) and one (T1) and two (T2) years of follow-up

\begin{tabular}{|c|c|c|c|c|c|c|}
\hline $\begin{array}{l}\text { Dependent } \\
\text { variable }\end{array}$ & $\begin{array}{l}\text { Predictor } \\
\text { variable }\end{array}$ & $\mathbf{R 2}$ & $\begin{array}{c}\mathrm{R}^{2} \\
\text { adjusted }\end{array}$ & $\begin{array}{c}\mathrm{R} 2 \\
\text { change }\end{array}$ & $F$ & $\mathbf{p}$ \\
\hline \multicolumn{7}{|l|}{ SOP (2) } \\
\hline & SDI (2) & 0.013 & 0.010 & 0.013 & 3.652 & 0.057 \\
\hline & SDI (0)/SDI (1) & 0.025 & 0.014 & 0.012 & 1.591 & 0.066 \\
\hline & $\operatorname{SOP}(0) / S O P(1)$ & 0.572 & 0.564 & 0.547 & 168.085 & $<0.001$ \\
\hline & DIS/DMS (2) & 0.041 & 0.034 & 0.041 & 5.677 & 0.004 \\
\hline & DIS/DMS (0)/DIS/DMS(1) & 0.062 & 0.041 & 0.021 & 1.474 & 0.211 \\
\hline & $\operatorname{SOP}(0) / \operatorname{SOP}(1)$ & 0.584 & 0.572 & 0.522 & 163.379 & $<0.001$ \\
\hline \multicolumn{7}{|l|}{ SPP (2) } \\
\hline & SDI (2) & 0.072 & 0.068 & 0.072 & 21.020 & $<0.001$ \\
\hline & SDI (0)/SDI (1) & 0.125 & 0.116 & 0.054 & 8.270 & $<0.001$ \\
\hline & $\operatorname{SPP}(0) / S P P(1)$ & 0.665 & 0.658 & 0.539 & 215.402 & $<0.001$ \\
\hline & DIS/DMS (2) & 0.121 & 0.115 & 0.121 & 18.725 & $<0.001$ \\
\hline & DIS/DMS (0)/DIS/DMS(1) & 0.143 & 0.124 & 0.022 & 1.700 & 0.150 \\
\hline & $\mathrm{SPP}(0) / \mathrm{SPP}(1)$ & 0.671 & 0.661 & 0.528 & 212.810 & $<0.001$ \\
\hline \multicolumn{7}{|l|}{ OOP (2) } \\
\hline & SDI (2) & 0.000 & -0.003 & 0.000 & 0.048 & 0.827 \\
\hline & SDI (0)/SDI (1) & 0.007 & -0.004 & 0.007 & 0.940 & 0.392 \\
\hline & OOP (0)/OOP (1) & 0.428 & 0.418 & 0.422 & 103.614 & $<0.001$ \\
\hline & DIS/DMS (2) & 0.006 & -0.001 & 0.006 & 0.831 & 0.436 \\
\hline & DIS/DMS (0)/DIS/DMS(1) & 0.020 & -0.001 & 0.014 & 0.978 & 0.420 \\
\hline & $\mathrm{OOP}(0) / \mathrm{OOP}(1)$ & 0.435 & 0.418 & 0.415 & 102.041 & $<0.001$ \\
\hline
\end{tabular}

$S O P=$ Self-Oriented Perfectionism; SPP = Socially-Prescribed Perfectionism; OOP = Other-Oriented Perfectionism; SDI = Sleep Disturbance Index; DIS = Difficulty Initiating Sleep; DMS = Difficulty Maintaining Sleep. 
to generalize a single failure to all aspects of the self, concern about criticism and censure from others, worry about future failures). Perfectionism has been associated with heightened arousal ${ }^{21}$ which in turn has been linked to delayed sleep-onset latency and reduced overall sleep time. Perfectionist individuals with sleep difficulties were reported to expect their sleep to be perfect and to become inordinately frustrated/anxious about any deviations from what is desirable. ${ }^{22,23}$ When someone consistently perceives that he is not having enough sleep, sleep-related anxiety, intrusive thoughts, and excessive worry may be fuelled (e.g. "I am losing control"; "I am not going to cope"). These people might also double the efforts during daytime to compensate for various perceived deficits. This may, in turn, lead to enhanced doubts about actions and concern over mistakes during daytime and heightened sensitivity to criticism from others. Over time, more pervasive perfectionist attitudes and behaviors may develop.

Previous studies exploring perfectionism dimensions and sleep difficulties in samples of undergraduate students reported no gender-related differences in mean perfectionism scores or in the association between perfectionism and sleep difficulties. ${ }^{2,3}$

One of the limitations of the present work is that we did not control for the effects of anxiety and depression, which could be related to perfectionism and insomnia. ${ }^{2}$ Other relevant psychological distress variables, such as dysfunctional cognitions (worry or rumination) and coping styles, were not assessed. In future studies, it is important to evaluate the bidirectional relationship between personality and sleep difficulties, considering these relevant variables.

The identification of the correlates of sleep difficulties and the collection of information concerning adequate means of action are of major importance. It is particularly relevant that certain personality traits correlate with particular cognitive aspects that play a central role in the explanation of complex mechanisms involved in the interplay between personality and sleep disturbances. Perfectionism has been associated with less frequent help-seeking behaviors. It has also been shown that perfectionism might interfere with the development of the therapeutic alliance, that it has an adverse effect in therapeutic outcomes across a range of psychiatric disorders, and that it contributes to relapse. ${ }^{24,25}$ Moreover, some studies addressing the restructuring of perfectionism-related cognitions suggest that the treatment of perfectionism leads to improvements in a wide range of psychopathologies. ${ }^{24}$

The literature about the stability of perfectionism is scarce. To our knowledge, the present work is the first study to investigate the absolute and relative stability of personality traits in relation to sleep difficulties in a non-clinical sample. Additionally, we used the largest follow-up time frame, which helps address such complex issues in a more consistent way.

\section{Acknowledgements}

Data for this report were drawn from a research project on perfectionism and obsessive-compulsive spectrum disorders, funded by the Science and
Technology Foundation (Fundação para a Ciência e a Tecnologia - FCT $37569 /$ PSI). The authors are grateful to all professors and students that collaborated in the study. We also want to thank for the anonymous reviewers' comments and suggestions, which contributed to the improvement of the manuscript. 
Disclosures

\begin{tabular}{|c|c|c|c|c|c|c|c|}
\hline $\begin{array}{l}\text { Writing group } \\
\text { member }\end{array}$ & Employment & $\begin{array}{l}\text { Research } \\
\text { grant }^{1}\end{array}$ & $\begin{array}{l}\text { Other research grant } \\
\text { or medical continuous } \\
\text { education }\end{array}$ & $\begin{array}{l}\text { Speaker's } \\
\text { honoraria }\end{array}$ & $\begin{array}{l}\text { Ownership } \\
\text { interest }\end{array}$ & $\begin{array}{l}\text { Consultant/ } \\
\text { Advisory } \\
\text { board }\end{array}$ & Other $^{3}$ \\
\hline Berta R. Maia & $\begin{array}{l}\text { Universidade } \\
\text { de Coimbra }\end{array}$ & - & - & - & - & - & - \\
\hline Maria J. Soares & $\begin{array}{l}\text { Universidade } \\
\text { de Coimbra }\end{array}$ & - & - & - & - & - & - \\
\hline Ana T. Pereira & $\begin{array}{l}\text { Universidade } \\
\text { de Coimbra }\end{array}$ & - & - & - & - & - & - \\
\hline $\begin{array}{l}\text { Mariana } \\
\text { Marques }\end{array}$ & $\begin{array}{l}\text { Universidade } \\
\text { de Coimbra }\end{array}$ & - & - & - & - & - & - \\
\hline Sandra C. Bos & $\begin{array}{l}\text { Universidade } \\
\text { de Coimbra }\end{array}$ & - & - & - & - & - & - \\
\hline Ana Gomes & $\begin{array}{c}\text { Universidade } \\
\text { de Aveiro }\end{array}$ & - & - & - & - & - & - \\
\hline José Valente & $\begin{array}{l}\text { Universidade } \\
\text { de Coimbra }\end{array}$ & - & - & - & - & - & - \\
\hline $\begin{array}{l}\text { Maria } \mathrm{H} . \\
\text { Azevedo }\end{array}$ & $\begin{array}{l}\text { Universidade } \\
\text { de Coimbra }\end{array}$ & - & - & - & - & - & - \\
\hline António Macedo & $\begin{array}{l}\text { Universidade } \\
\text { de Coimbra }\end{array}$ & - & - & - & - & - & - \\
\hline
\end{tabular}

* Modest

** Significant

*** Significant: Amounts given to the author's institution or to a colleague for research in which the author has participation, not directly to the author. For more information, see Instructions for Authors.

\section{References}

1. Hewitt PL, Flett GL. Perfectionism in the self and social contexts: conceptualization, assessment and association with psychopathology. J Pers Soc Psychol. 1991;60(3):456-70.

2. de Azevedo MH, Soares MJ, Bos SC, Gomes AA, Maia B, Marques M, Pereira AT, Macedo A. Perfectionism and sleep disturbance. World J Biol Psychiatry. 2009; 10(3):225-33.

3. Azevedo MH, Bos SC, Soares MJ, Marques M, Pereira AT, Maia B, Gomes AA, Macedo A. Longitudinal study on perfectionism and sleep disturbance. World J Biol Psychiatry. 2010;11(2 Pt 2):476-85.

4. Lundh LG, Broman J, Hetta J, Saboonchi F. Perfectionism and insomnia. Scand $J$ Behav Ther. 1994;23(1):3-18.

5. Jansson-Frojmark M, Linton SJ. Is perfectionism related to preexisting and future insomnia? A prospective study. Br J Clin Psychol. 2007;46(Pt 1):119-24.

6. Vincent NK, Walker JR. Perfectionism and chronic insomnia. J Psychosom Res. 2000;49(5):349-54.

7. Lundh LG, Broman JE. Insomnia as an interaction between sleep-interfering and sleep-onset insomnia. J Psychosom Res. 2000;49(5):299-310.

8. Frost RO, Marten P, Lahart C, Rosenblate R. The dimensions of perfectionism. Cognit Ther Res. 1990;14:449-68.

9. Van de Laar M, Verbeek I, Pevernagie D, Aldenkamp A, Overeem S. The role of personality traits in insomnia. Sleep Med Rev. 2010;14(1):61-8.

10. Santor DA, Bagby RM, Joffe RT. Evaluating stability and change in personality and depression. J Pers Soc Psychol. 1997;73(6):1354-62.

11. Cox BJ, Enns MW. Relative stability of dimensions of perfectionism in depression. Can J Behav Science. 2003;35(2):124-32.

12. Rice KG, Aldea MA. State dependence and trait stability of perfectionism: a short-term longitudinal study. J Couns Psychol. 2006;53(2):205-12.

13. Zuroff DC, Blatt SJ, Sanislow CA, Bondi CM, Pilkonis PA. Vulnerability to depression: re-examining state dependence and relative stability. J Abnorm Psychol. 1999;108(1):76-89.

14. Macedo A, Pocinho F, Soares MJ, Dourado A, Campos C, Domingues O, Azevedo MH. Perfectionism: a phenotype dimension common to obsessive and eating disorders? Psiquiatr Clin. 2002;23:163-74.
15. Soares MJ, Gomes A, Macedo A, Santos V, Azevedo MH. Escala multidimensional de perfeccionismo: Adaptação à população Portuguesa. Rev Portuguesa Psicossom. 2003;5(1):46-55.

16. Green SB, Salkind NJ, Akey TM. Using SPSS for Windows. Analysing and understanding data. 2nd ed. Upper Saddle River, New Jersey: Prentice Hall; 1999.

17. Cohen J. A power primer. Psychol Bull. 1992;112(1):155-9.

18. Shafran R, Mansell W. Perfectionism and psychopathology: a review of research and treatment. Clin Psychol Rev. 2001;21(6):879-906.

19. Hewitt PL, Flett GL, Ediger E. Perfectionism and depression: longitudinal assessment of a specific vulnerability hypothesis. J Abnorm Psychol. 1996;105(2):276-80.

20. Bousman de L. (2007). The fine line of perfectionism: is it a strength or a weakness in the workplace? Dissertation presented to the Faculty of The Graduate College, University of Nebraska.

21. Blatt SL. The destructiveness of perfectionism: implications for the treatment of depression. Am Psychol. 1995;50(12)1003-20.

22. Broman J, Hetta J. Perceived pre-sleep arousal in patients with persistent psychophysiology and psychiatric insomnia. Nord J Psychiatry. 1994;48(3):203-7. 23.Nicassio PM, Mendlowitz DR, Fussell JJ, Petras L. The phenomenology of the pre-sleep state: the development of the pre-sleep arousal scale. Behav Res Ther. 1985;23(3):263-71.

24. Pleva J, Wade TD. Guided self-help versus pure self-help for perfectionism: a randomised controlled trial. Behav Res Ther. 2006;45(5):849-61.

25. Goldner EM, Cockell SJ, Srikameswaran S. Perfectionism and eating disorders. In: Flett GL, Hewitt PL. Perfectionism. Theory, research and treatment. Washington DC: American Psyhcological Association; 2002. 